\title{
Viabilidade financeira da utilização de quatro ordenhas nos primeiros 21 dias da lactação em vacas mestiças F1 Holandês/Zebu
}

\author{
[Financial viability analyses of four milkings in the first 21 days of lactation in F1 crossbred \\ Holstein-Zebu cows]
}

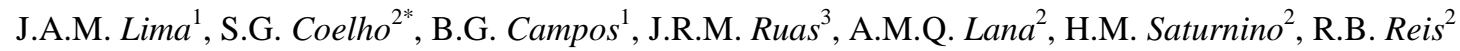 \\ ${ }^{1}$ Aluna de pós-graduação - EV-UFMG - Belo Horizonte, MG \\ ${ }^{2}$ Escola de Veterinária - UFMG \\ Caixa Postal 567 \\ 30123-970 - Belo Horizonte, MG \\ ${ }^{3}$ EPAMIG - Belo Horizonte, MG
}

\begin{abstract}
RESUMO
Avaliou-se financeiramente o efeito de quatro ordenhas diárias nos primeiros 21 dias da lactação, seguidas de duas ordenhas diárias, com ou sem a sucção de leite pelo bezerro em um dos tetos durante a ordenha. Foram utilizadas 53 vacas F1 Holandês/Zebu multíparas. A produção e a composição do leite foram mensuradas a cada quatro dias até o $33^{\circ}$ dia da lactação e, posteriormente, a cada 15 dias. Como indicador do desempenho financeiro dos diferentes grupos, foi utilizada a margem bruta. O experimento foi desenvolvido em delineamento inteiramente ao acaso, em arranjo fatorial $2 \times 2$. As produções médias de leite foram 16,7, 17,2, 19,0 e 18,9kg/d $(\mathrm{P}<0,01)$ para vacas ordenhadas duas e quatro vezes por dia, com ou sem a sucção do leite pelo bezerro durante a ordenha, respectivamente. $\mathrm{O}$ aumento da frequência de ordenhas nos primeiros 21 dias da lactação proporcionou incremento na produção de dois litros/dia e $17,3 \%$ na margem bruta estimada com a venda de leite.
\end{abstract}

Palavras-chave: vaca de leite, frequência de ordenhas, viabilidade financeira

\begin{abstract}
Fifty-three F1 crossbred Holstein-Zebu cows were used to evaluate financially the effects of four daily milkings until lactation day 21, and after this day two milkings, with or without suckling by the calf in one teat during milking. Milk production and composition were measured each four days until lactation day 33, and then each 15 days until the end of lactation. The experiment followed a completely randomized design in a $2 \times 2$ factorial. To analyze the financial viability of the different groups, the gross margin was used, as financial indicator. Milk productions were 16.7, 17.2, 19.0, and 18.9kg/day $(P<0.01)$ for cows milked twice or four times a day with or without suckling by the calf, respectively. The rise of milking frequency increased milk production in two liters per day, and in $17.3 \%$ of estimated gross margin from the sale of milk.
\end{abstract}

Keywords: dairy cow, financial viability, milking frequency

\section{INTRODUÇÃO}

O aumento da frequência de ordenhas com o objetivo de aumentar a produção de leite tem

Recebido em 16 de dezembro de 2010

Aceito em 22 de fevereiro de 2011

*Autor para correspondência (corresponding author)

E-mail: sandra@vet.ufmg.br

Projeto Financiado pela FAPEMIG-CVZ APQ-2413-5.04/07 sido empregado ao longo de toda a lactação tanto para animais da raça Holandesa (Erdman e Varner, 1995) quanto para animais mestiços com variada composição genética (Ruas et al., 2006). Estudos recentes em vacas da raça Holandesa 
relataram aumento na produção de leite em resposta ao aumento da frequência de ordenhas nos primeiros dias da lactação, com persistência deste efeito após o retorno ao manejo de ordenha convencional (Hale et al., 2003; Dahl et al., 2004; Wall e McFadden, 2007).

O objetivo de qualquer tecnologia adotada em uma fazenda de gado leiteiro é aumentar a rentabilidade. Portanto, antes da adoção de uma nova tecnologia, o produtor deve considerar o custo adicional de sua implementação, bem como a estimativa de retorno financeiro e/ou econômico. No caso do aumento de frequência de ordenhas, a produção de leite adicional é acompanhada por aumento no custo alimentar e no operacional com hora/ordenha, além de outros fatores que devem ser considerados, como o tamanho e a saúde do rebanho e, principalmente, o preço pago pelo leite (Maltz et al., 2003).

Moraes et al. (2004) relataram rentabilidade de $20,2 \%$ e $37,6 \%$ no primeiro e segundo anos de avaliação de um sistema de produção de leite com gado mestiço F1 Holandês/Zebu que é expressiva se comparada à obtida por Schiffler (1998), em sistemas de produção de leite com gado Holandês puro, aproximadamente de $6 \%$ ao ano. Wall e McFadden (2007) estimaram aumento do lucro líquido de cerca de 93 dólares por vaca ao ano, quando as vacas foram ordenhadas quatro vezes ao dia nas primeiras três semanas da lactação e, posteriormente, retornaram a duas ordenhas diárias. Soberón et al. (2010) observaram maior rentabilidade tanto em pequenos quanto em grandes rebanhos, em que foram utilizados a mesma metodologia de Wall e McFadden, (2007). Portanto, assumindo que não há efeito negativo sobre a saúde animal e sobre o desempenho reprodutivo ou produtivo da vaca em posteriores lactações, o aumento da frequência de ordenha nos primeiros 21 dias da lactação apresenta-se como ferramenta de manejo de fácil adoção e com grande potencial em incrementar o lucro da atividade leiteira.

Dessa forma, este estudo teve como objetivo estudar os efeitos do aumento do número de ordenhas e da sucção ou não do leite pelos bezerros, no início da lactação, sobre a produção de leite, bem como avaliar a relação custo/benefício da aplicação dessa técnica em vacas F1 Holandês/Zebu.

\section{MATERIAL E MÉTODOS}

O experimento foi realizado na Fazenda Experimental da Empresa de Pesquisa Agropecuária de Minas Gerais, localizada no município de Felixlândia, região central do estado de Minas Gerais. Foram utilizadas 53 vacas multíparas, mestiças F1 Holandês/Zebu. Todos os animais receberam o mesmo manejo alimentar, que consistiu de pastejo de Brachiaria decumbens e Brachiaria brizanta e suplementação com silagem de milho no período seco e concentrado fornecido a partir de produção diária superior a $8 \mathrm{~kg}$ de leite.

Os animais foram distribuídos em quatro grupos: grupo 1 - 12 vacas ordenhadas duas vezes ao dia, do primeiro ao $21^{\circ}$ dia da lactação, sendo os bezerros apresentados somente para o apojo (sucção do leite somente antes da colocação das teteiras); grupo 2 - 13 vacas ordenhadas duas vezes ao dia, do primeiro ao $21^{\circ}$ dia da lactação, com sucção de leite pelos bezerros durante a ordenha em apenas um dos tetos anteriores; grupo 3 - 15 vacas ordenhadas quatro vezes ao dia, do primeiro ao $21^{\circ}$ dia da lactação, sendo os bezerros apresentados somente para o apojo; grupo $4-13$ vacas ordenhadas quatro vezes ao dia, do primeiro ao $21^{\circ}$ dia da lactação, com sucção de leite pelos bezerros durante a ordenha em apenas um dos tetos anteriores.

A partir do $22^{\circ}$ dia da lactação, todas as vacas foram ordenhadas duas vezes ao dia, e os bezerros apresentados apenas para o apojo. As ordenhas foram realizadas no seguinte esquema: as vacas dos grupos 3 e 4, nas ordenhas da manhã e da tarde, foram as primeiras a serem ordenhadas, seguidas dos animais pertencentes aos grupos 1 e 2 e dos demais lotes de vacas em lactação da fazenda. Após o término da ordenha dos lotes de animais não pertencentes ao experimento, as vacas dos grupos 3 e 4 foram novamente ordenhadas. Os intervalos de ordenhas para os grupos 1 e 2 foram de sete e 17 horas, e nos grupos 3 e 4 de duas, cinco, 1,3 e 15,3 horas, aproximadamente. Após a ordenha da manhã e da tarde, os bezerros fizeram a sucção do leite residual. A produção e a composição do leite foram mensuradas a cada quatro dias até o $33^{\circ}$ dia da lactação e, a partir daí, a cada 15 dias, até o final da lactação. 
O experimento foi desenvolvido em delineamento estatístico inteiramente ao acaso, com no mínimo 12 repetições por grupo em arranjo fatorial $2 \times 2$, sendo dois métodos de ordenha (com e sem sucção do leite pelo bezerro) e duas frequências diárias (duas ou quatro ordenhas, essa última aplicada até o $21^{\circ}$ dia da lactação). A produção de leite foi avaliada até os 250 dias, quando a lactação foi considerada encerrada.

Com o intuito de visualizar o impacto da resposta financeira no sistema de produção de leite comercial, as médias de produção de leite obtidas em cada grupo foram utilizadas em simulação com rebanho composto de 136 vacas em lactação por grupo, correspondente ao rebanho em lactação da fazenda. Os preços de leite e dos insumos em geral, utilizados para composição da receita e custo operacional efetivo, foram referentes aos preços praticados na fazenda no ano de 2008, no período experimental.

Para análise da viabilidade financeira dos diferentes grupos, foi utilizada a margem bruta como indicador de desempenho financeiro da atividade leite, calculada pela equação: Margem Bruta $=$ Receita total - Custo operacional efetivo.

O modelo analítico utilizado para estimar a receita foi: Receita $=(P L i . X i j)$, em que:

$\mathrm{PLi}=$ preço médio anual por litro de leite por grupo i;

Xij = média de leite por animal $\mathrm{j}$ em cada grupo i.

Receita de venda do leite: a produção foi calculada pela multiplicação do número médio de vacas em lactação pela média de produção de leite observada em cada grupo. O preço do leite foi composto pelo preço base, acrescido das bonificações por volume, porcentagem de gordura e proteína, recebidos em 2008. A bonificação por contagem bacteriana e pela contagem de células somáticas (CCS) foi fixa para todos os grupos, entrando na composição do preço base, uma vez que estes parâmetros não foram avaliados no presente estudo.

O modelo analítico utilizado para estimar o custo operacional efetivo (COE) foi:

$\mathrm{COE}=\sum[(\mathrm{CD} \cdot \mathrm{Xij})+(\mathrm{CO} \cdot \mathrm{Hij})+\mathrm{Kn}]$, em que: $\mathrm{CD}=$ custo da dieta por litro de leite;
Xij = média de leite por animal $\mathrm{j}$ em cada grupo i;

$\mathrm{CO}=$ custo hora ordenha;

Hij = horas ordenha por animal $\mathrm{j}$ em cada grupo i;

$\mathrm{Kn}=$ custos dos fatores mantidos constantes, assumindo que os demais componentes do COE foram comuns aos diferentes grupos.

Custo alimentar/vaca: custo alimentar médio anual por litro de leite, multiplicado pela média de produção de leite observada em cada grupo.

Custo médio hora/ordenha: somatório anual de despesas relacionadas ao processo de ordenha, dividido pelo número de horas anuais de utilização do equipamento de ordenha, obtendo, assim, o custo médio hora/ordenha. Os custos relacionados ao processo de ordenha foram: energia elétrica, mão de obra, gerenciamento, produtos de limpeza, insufladores, filtro ordenha, despesa com manutenção da ordenha e outros.

\section{RESULTADOS E DISCUSSÃO}

Os grupos submetidos a quatro ordenhas encerraram a lactação com produção total média de $4.489 \mathrm{~kg}$ de leite, e os submetidos a duas ordenha $3.967 \mathrm{~kg}$ leite. O aumento de produção nos grupos ordenhados quatro vezes em relação aos ordenhados apenas duas vezes foi de $4,0 \mathrm{~kg} / \mathrm{d}$ durante os primeiros 21 dias da lactação e de 1,5kg/dia de leite após esse período. Também não foi observado efeito da sucção de leite pelos bezerros (Tab. 1). Os percentuais de gordura e sólidos totais, produção de leite corrigida para 3,5\% de gordura e leite corrigido para sólidos totais foram mais elevados nos grupos com quatro ordenhas $(\mathrm{P}<0,01)$. A gordura do leite, por ter menor densidade em relação à proteína e à lactose, apresenta variações percentuais ao longo das ordenhas, aumentando ao final destas e no leite que fica retido no úbere (Reis et al., 2007). Dessa forma, com o aumento da frequência de ordenha, foi possível retirar do úbere uma fração de leite com maior valor de gordura, o que alterou a concentração final deste sólido e, consequentemente, os valores encontrados para leite corrigido para $3,5 \%$ de gordura e leite corrigido para sólidos totais, nestes mesmos grupos, durante o período de tratamento. Mais ainda, a manutenção dos maiores valores de gordura e, consequentemente, dos outros componentes do leite relacionados a ele, após o 
retorno a duas ordenhas, pode estar relacionada ao aumento do número de células e à atividade enzimática, estimulados pelo maior número de ordenhas apenas no início da lactação, descritos, respectivamente, por Hillerton et al. (1990) e Hale et al. (2003), pois a glândula mamária teria maior número e atividade enzimática para a produção do leite e dos outros componentes do leite.

Tabela 1. Médias da produção e composição de leite durante a lactação de vacas F1 Holandês/Zebu ordenhadas duas ou quatro vezes durante os primeiros 21 dias da lactação com apojo (BA) ou mamada dos bezerros (BM), seguidas por duas ordenhas no período remanescente da lactação

\begin{tabular}{|c|c|c|c|c|c|c|c|c|}
\hline & \multicolumn{2}{|c|}{ Duas ordenhas } & \multicolumn{2}{|c|}{ Quatro ordenhas } & \multirow[b]{2}{*}{ DP } & \multicolumn{3}{|c|}{ Probabilidade } \\
\hline & $\mathrm{BA}$ & $\mathrm{BM}$ & BA & $\mathrm{BM}$ & & Ord & Bez & Ord*Bez \\
\hline Leite $\mathrm{kg} / \mathrm{d}$ & 17,21 & 16,70 & 18,94 & 19,04 & 5,15 & $<0,01$ & $\mathrm{~ns}$ & $\mathrm{~ns}$ \\
\hline Gordura \% & 3,79 & 3,74 & 4,03 & 4,00 & 0,73 & $<0,01$ & ns & ns \\
\hline Sólidos totais \% & 12,51 & 12,52 & 12,74 & 12,68 & 0,91 & $<0,01$ & ns & ns \\
\hline LCG kg/d & 16,76 & 15,65 & 18,94 & 19,29 & 4,64 & $<0,01$ & ns & $<0,05$ \\
\hline LCST kg/d & 16,76 & 15,73 & 18,74 & 19,05 & 4,43 & $<0,01$ & ns & $<0,05$ \\
\hline
\end{tabular}

ns: não significativo; LCG: leite corrigido para 3,5\% de gordura; LCST: leite corrigido para sólidos totais; DP: desvio-padrão; CV: coeficiente de variação (\%).

Ord: efeito da frequência de ordenha; Bez: efeito da amamentação do bezerro durante a ordenha; Ord*Bez: interação frequência de ordenha versus amamentação do bezerro durante a ordenha. Teste Tukey $(\mathrm{P} \leq 0,05)$.

A receita mensal gerada com a venda do leite foi maior nos grupos submetidos a quatro ordenhas, em função da maior produção de leite e do maior preço por litro de leite (Tab. 2). O grupo quatro ordenhas com mamada do bezerro durante a ordenha apresentou maior receita mensal, $\mathrm{R} \$ 628,14$, do que o grupo quatro ordenhas somente com o apojo do bezerro. O preço médio por litro de leite foi maior em razão da maior bonificação recebida por volume e gordura.

Tabela 2. Receita mensal com a venda de leite estimada para os diferentes grupos

\begin{tabular}{ccccc}
\hline Grupo & R\$/litro & Média litros/vaca & Litros/dia & Receita mensal (R\$) \\
\hline 1 & 0,73 & 17,2 & 2339 & $51.574,74$ \\
2 & 0,73 & 16,7 & 2271 & $50.075,34$ \\
3 & 0,74 & 18,9 & 2570 & $57.759,54$ \\
4 & 0,74 & 19,0 & 2584 & $58.387,68$ \\
\hline
\end{tabular}

Preços referentes a 2008, não corrigidos monetariamente. Grupos 1 e 2: duas ordenhas com bezerro fazendo apojo e sucção de leite durante a ordenha, do primeiro ao $21^{\circ}$ dia da lactação, respectivamente. Grupos 3 e 4 : quatro ordenhas com bezerro fazendo apojo e suç̧ão de leite durante a ordenha, do primeiro ao $21^{\circ}$ dia da lactação, respectivamente.

Com relação aos custos operacionais efetivos contabilizados nesta avaliação, como hora/ordenha e custo alimentar/vaca, estes foram maiores nos grupos submetidos a quatro ordenhas em função das horas adicionais no processo de ordenha e ao aumento de consumo de alimento em resposta ao aumento da produção de leite. O acréscimo no custo mensal hora/ordenha de $\mathrm{R} \$ 353,18$ foi inexpressivo (Tab. 3 e 4), quando comparado ao aumento de produção de leite e receita observados nestes grupos. $\mathrm{O}$ pequeno incremento no custo hora/ordenha é justificado pelo fato de o manejo de ordenha adicional acontecer somente nos primeiros 21 dias da lactação, equivalente, em média, a 11 vacas sendo ordenhadas a mais por dia, considerando-se o rebanho de 136 vacas citado neste exemplo, com duração média de lactação de 250 dias.

Tabela 3. Custo mensal hora/ordenha estimado para os diferentes grupos

\begin{tabular}{ccccc}
\hline Grupo & Hora/ordenha (R\$) & Total horas & Horas adicionais & Custo mensal (R\$) \\
\hline 1 & 28,95 & 151,65 & 0 & $4.390,27$ \\
2 & 28,95 & 151,65 & 0 & $4.390,27$ \\
3 & 28,95 & 151,65 & 12,2 & $4.743,45$ \\
4 & 28,95 & 151,65 & 12,2 & $4.743,45$ \\
\hline
\end{tabular}

Preços referentes a 2008, não corrigidos monetariamente. Grupos 1 e 2: duas ordenhas com bezerro fazendo apojo e sucção de leite durante a ordenha, do primeiro ao $21^{\circ}$ dia da lactação, respectivamente. Grupos 3 e 4: quatro ordenhas com bezerro fazendo apojo e suç̧ão de leite durante a ordenha, do primeiro ao $21^{\circ}$ dia da lactação, respectivamente. 
O custo alimentar vaca/dia foi calculado a partir do custo alimentar/litro de leite. Dessa forma, o custo alimentar vaca/dia aumentou proporcionalmente ao aumento de produção de leite, verificando-se maior custo nos grupos submetidos a quatro ordenhas (Tab. 4). Este comportamento no consumo de alimentos é embasado pela literatura, em que estudos observaram aumento de consumo em ajuste ao aumento de produção de leite (Bauman, 1992; McGuire et al., 2004; Baumgard et al., 2006). No entanto, é importante ressaltar que, na prática, o aumento no custo alimentar vaca/dia não ocorre linearmente em resposta ao aumento de produção de leite, uma vez que se observa efeito de diluição do custo alimentar/litro de leite com aumento de produção. A explicação é simples: as exigências nutricionais para mantença não se alteram com o aumento de produção de leite, porque são basicamente dependentes do peso do animal. Dessa forma, a vaca torna-se mais eficiente porque os nutrientes consumidos a mais serão destinados à produção de leite, diluindo, assim, o seu custo fixo ou a mantença.

Tabela 4. Custo mensal com a alimentação das vacas de leite para os diferentes grupos

\begin{tabular}{ccccc}
\hline Grupo & $\begin{array}{c}\text { Custo dieta/litro de } \\
\text { leite (R\$) }\end{array}$ & Custo dieta vaca/dia (R\$) & Custo dieta /mês (R\$) & $\begin{array}{c}\text { \% relação à } \\
\text { receita }\end{array}$ \\
\hline 1 & 0,30 & 5,16 & $21.263,33$ & $52,85 \%$ \\
2 & 0,30 & 5,01 & $20.645,21$ & $54,43 \%$ \\
3 & 0,30 & 5,67 & $23.364,94$ & $48,10 \%$ \\
4 & 0,30 & 5,70 & $23.488,56$ & $47,84 \%$ \\
\hline
\end{tabular}

Preços referentes a 2008, não corrigidos monetariamente. Grupos 1 e 2: duas ordenhas com bezerro fazendo apojo e suç̧ão de leite durante a ordenha, do primeiro ao $21^{\circ}$ dia da lactação, respectivamente. Grupos 3 e 4: quatro ordenhas com bezerro fazendo apojo e sucção de leite durante a ordenha, do primeiro ao $21^{\circ}$ dia da lactação, respectivamente.

Tomando-se a margem bruta como indicador, torna-se expressivo o incremento financeiro proporcionado pelo aumento da frequência de ordenha no $21^{\circ}$ dia de lactação (Tab. 5). Ao se comparar os grupos submetidos a quatro e a duas ordenhas, a diferença média na margem bruta foi positiva na ordem de $\mathrm{R} \$ 3.982,24$ para os animais submetidos a quatro ordenhas, o que equivale ao aumento médio de $17,3 \%$ na margem bruta da atividade leite.

Tabela 5. Margem bruta mensal estimada para produção de leite nos diferentes grupos

\begin{tabular}{cccccc}
\hline Grupo & Receita leite (R\$) & Custo horas/ordenha (R\$) & $\begin{array}{c}\text { Custo } \\
\text { alimentar (R\$) }\end{array}$ & $\begin{array}{c}\text { Margem } \\
\text { bruta (R\$) }\end{array}$ & $\begin{array}{c}\text { Diferença da } \\
\text { menor } \\
\text { margem (R\$) }\end{array}$ \\
\hline 1 & $51.574,74$ & $4.390,27$ & $21.263,33$ & $25.921,14$ & 881,28 \\
2 & $50.075,34$ & $4.390,27$ & $20.645,21$ & $25.039,86$ & 0,00 \\
3 & $57.759,54$ & $4.743,45$ & $23.364,94$ & $29.651,15$ & $4.611,29$ \\
4 & $58.387,68$ & $4.743,45$ & $23.488,56$ & $30.155,62$ & $5.115,76$ \\
\hline
\end{tabular}

Preços referentes a 2008, não corrigidos monetariamente. Grupos 1 e 2: duas ordenhas com bezerro fazendo apojo e sucção de leite durante a ordenha, do primeiro ao $21^{\circ}$ dia da lactação, respectivamente. Grupos 3 e 4: quatro ordenhas com bezerro fazendo apojo e sucção de leite durante a ordenha, do primeiro ao $21^{\circ}$ dia da lactação, respectivamente.

Ao se considerar a produção individual por lactação, observa-se aumento médio de 500 litros na lactação a favor dos grupos submetidos a quatro ordenhas, equivalente a incremento de $\mathrm{R} \$ 365,00$ por vaca.

\section{CONCLUSÕES}

A utilização de quatro ordenhas melhorou o desempenho técnico e econômico no rebanho composto por animais F1 Holandês/Zebu, justificando, dessa forma, sua implantação em sistemas similares ao apresentado neste estudo. 


\section{REFERÊNCIAS BIBLIOGRÁFICAS}

BAUMGARD, L.H.; ODENS, L.J.; KAY, J.K. et al. Does negative energy balance (NEBAL) limit milk synthesis in early lactation. In: ANNUAL SOUTHWEST NUTRITION \& MANAGEMENT CONFERENCE PROCEEDINGS, 21., 2006, Tempe, Arizona.

BAUMAN, D.E. Bovine somatotropin: review of an emerginig animal technology. J. Dairy Sci., v.75, p.3433-3451, 1992.

DAHL, G. E.; WALLACE, R. L.; SHANKS, R. D. et al. Effects of frequent milking in early lactation on milk yield and udder health. J. Dairy Sci., v.87, p.882-885, 2004.

ERDMAN, R. A.; VARNER, M. Fixed yield responses to increased milking frequency. $J$. Dairy Sci., v.78, p.1199-1203, 1995.

HALE, S.A.; CAPUCO, A.V.; ERDMAN, R.A. Milk yield and mammary growth effects due to increased milking frequency during early lactation, J. Dairy Sci., v.86, p.2061-2071, 2003.

HILLERTON, J.E.; KNIGHT, C.H.; TURVEY, A. et al. Milk yield and mammary function in dairy cows milked four times daily. J. Dairy Res., v.57, p.285-294, 1990.

MALTZ, E.; LIVSHIN, N.; ANTLER, A. et al. Variable milking frequency in large dairies: performance and economic analysis - models and experiments. Precision Livest. Farming, v.1, p.113-118, 2003.
McGUIRE, M.A.; MARK, A.; THEURER, M. et al. Controlling energy balance in early lactation. Adv. Dairy Technol., v.16, p.241, 2004.

MORAES, A.C.A.; COELHO, S.G.; RUAS, J.R.M. et al. Estudo técnico e econômico de um sistema de produção de leite com gado mestiço F1 Holandês-Zebu. Arq. Bras. Med. Vet. Zootec., v.56, p.745-749, 2004.

RUAS, J.R.M.; BRANDÃO, F.Z.; FILHO, J.M.S. et al. Influência da frequência de ordenhas diárias sobre a eficiência produtiva de vacas mestiças Holandês-Zebu e o desempenho dos seus bezerros. Rev. Bras. Zootec., v.35, p.428434, 2006.

SCHIFFLER, E.A. Análise de eficiência técnica e econômica de sistemas de produção de leite na região de São Carlos, São Paulo. 1998. 128f. Dissertação (Mestrado) - Universidade Federal de Viçosa, Viçosa, MG.

REIS, G.L.; ALVES, A.A.; LANA, A.M.Q. et al. Procedimentos de coleta de leite cru individual e sua relação com a composição físico-quimica e a contagem de células somáticas. Cienc. Rural, v.37, p.1134-1138, 2007.

SOBERÓN, F.; LUKAS, J.L.; VAN AMBURGH, M.E. et al. Effects of increased milking frequency on metabolism and mammary cell proliferation in Holstein dairy cows. J. Dairy Sci., v.93, p.565-573, 2010.

WALL, E.H.; McFADDEN T.B. Optimal timing and duration of unilateral frequent milking during early lactation of dairy cows. J. Dairy Sci., v.90, p.5042-5048, 2007. 